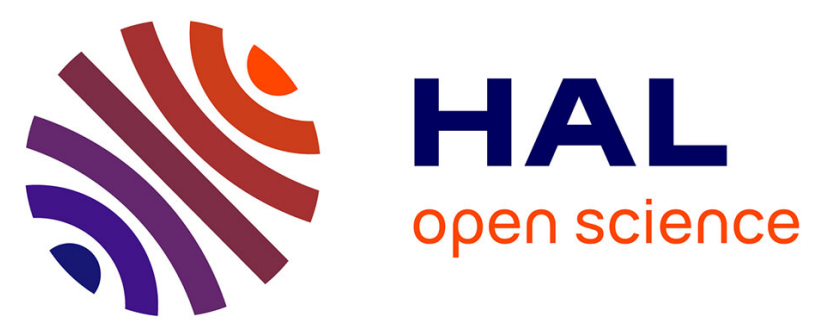

\title{
Infected breast milk associated with late-onset and recurrent group $B$ streptococcal infection in neonatal twins: a genetic analysis
}

Arnaud Gagneur, Geneviève Héry-Arnaud, Séverine Croly-Labourdette, Gisèle Gremmo-Feger, Sophie Vallet, Jacques Sizun, Roland Quentin, Didier Tandé

\section{To cite this version:}

Arnaud Gagneur, Geneviève Héry-Arnaud, Séverine Croly-Labourdette, Gisèle Gremmo-Feger, Sophie Vallet, et al.. Infected breast milk associated with late-onset and recurrent group B streptococcal infection in neonatal twins: a genetic analysis. European Journal of Pediatrics, 2009, 168 (9), pp.11551158. 10.1007/s00431-008-0903-y . hal-00557543

\section{HAL Id: hal-00557543 \\ https://hal.univ-brest.fr/hal-00557543}

Submitted on 21 Jan 2011

HAL is a multi-disciplinary open access archive for the deposit and dissemination of scientific research documents, whether they are published or not. The documents may come from teaching and research institutions in France or abroad, or from public or private research centers.
L'archive ouverte pluridisciplinaire HAL, est destinée au dépôt et à la diffusion de documents scientifiques de niveau recherche, publiés ou non, émanant des établissements d'enseignement et de recherche français ou étrangers, des laboratoires publics ou privés. 
1 Infected breast milk associated with late-onset and recurrent group B

2 streptococcal infection in neonatal twins: a genetic analysis

4 Arnaud Gagneur ${ }^{1,2}$, Geneviève Héry-Arnaud ${ }^{3}$, Séverine Croly-Labourdette ${ }^{1}$,

5 Gisèle Gremmo-Feger ${ }^{1}$, Sophie Vallet ${ }^{3}$, Jacques Sizun ${ }^{1}$, Roland Quentin ${ }^{4}$,

$6 \quad$ Didier Tandé ${ }^{3}$

7

8 1'Département de Pédiatrie, Hôpital Morvan, Centre Hospitalo-Universitaire,

9 Brest, France

$10{ }^{2}$ Département de Pédiatrie, CHUS Sherbrooke, Québec, Canada

$11{ }^{3}$ Département de Microbiologie, EA 3882 Laboratoire Universitaire de

12 Biodiversité et Ecologie Microbienne, Hôpital Morvan, Centre Hospitalo-

13 Universitaire, Brest, France ;

$14{ }^{4}$ Service de Bactériologie, Hôpital Trousseau, Centre Hospitalier Régional et 15 Universitaire, Tours, France ;

18 Correspondance:

19 Dr Arnaud Gagneur

20 Département de Pédiatrie, Unité de Néonatalogie, CHUS Fleurimont 3001,

21 12ème avenue nord, Sherbrooke (QC), J1H 5N4, Canada.

22 E-mail: arnaud.gagneur@usherbrooke.ca

23

24 Acknowledgements

25 We wish to thank Tracey Montagnon for reviewing the manuscript. 


\section{Summary}

29 Asymptomatic excretion of group B streptococcus (GBS) in breast milk may be

30 an under-recognised cause of neonatal and recurrent infection. We report the

31 case of late-onset and recurrent infection in newborn twins resulting from

32 ingestion of maternal breast milk infected with GBS. Genetic analysis of 33 isolates is equally presented.

34

35 Key-words: group B streptococcus; breast milk; recurrent infection; genetic 36 analysis; late-onset disease 37 38 
41 Group B streptococcus (GBS) is the most frequent cause of neonatal sepsis

42 and meningitis. Most cases occur in the first week of life and are related to vaginal carriage in the mother (early-onset disease). Conversely, late-onset

44 disease (between 1 week and 3 months of age) is less common and is hand-

45 transmitted by nursery personnel or via other nosocomial or community 46 pathways [6]. Late- onset and recurrent disease have also been reported with

47 the ingestion of infected mother's milk, with some cases confirmed using 48 molecular techniques $[2-4,7,9,13]$. We report in this article the case of late49 onset and recurrent infection in newborn twins resulting from ingestion of 50 maternal breast milk infected with GBS. In this case genetic analysis

51 demonstrated that all GBS isolates (maternal breast milk and vaginal isolates; 52 twin CSF and blood isolates) were identical, but additional genetic analysis 53 also revealed that the GBS isolates were of a particularly virulent clone 54 belonging to serotype III, as are $90 \%$ of the strains responsible for late- onset 55 disease [3].

\section{Case report}

59 Premature twins were delivered by spontaneous vaginal delivery at 31 weeks 60 gestation, 48 hours following membrane rupture. The 26 year- old mother,

61 gravida 1, para 2, received intrapartum antibiotic prophylaxis (single dose of 62 penicillin $\mathrm{G}$ ) due to positive vaginal GBS culture at 30 weeks gestation. Twin 631 , female, weighed $1600 \mathrm{~g}$ with an Apgar score of 10/10 at 1 and 5 minutes.

64 No respiratory failure was noted and early enteral feeding was started with raw 65 breast milk at day 1 . Total enteral alimentation with breast milk was obtained 66 at day 6. Twin 2, male, weighed $1720 \mathrm{~g}$ with an Apgar score of $4 / 9$ at 1 and 5 
67 minutes. He was intubated shortly after birth due to respiratory failure and

68 received one dose of surfactant. By the $3^{\text {rd }}$ hour of life, he was extubated and

69 nasal CPAP was initiated. Enteral alimentation with raw breast milk was

70 introduced at day 4. Antibiotic therapy with cefotaxime and amoxicillin was

71 prescribed for both infants due to incomplete prepartum antibiotic prophylaxis

72 and stopped at day 2 due to negative C- reactive protein as well as negative

73 gastric and blood cultures. Cerebral ultrasound examination was normal for

74 both infants at day 4 .

75 On day 13, Twin 2 developed cardio-respiratory instability and blood culture 76 tested positive for group B streptococcus. Meningitis was suspected due to 77 elevated CSF protein concentration. Until day 16 Twin 1 was asymptomatic 78 with negative C- reactive protein control. On day 16, she developed 79 respiratory distress and subsequent blood and cerebrospinal fluid cultures 80 tested positive for GBS. Antibiotic treatment with amoxicillin at $200 \mathrm{mg} /$ day 81 was prescribed for 14 days, in association with an aminoglycoside during the 82 first 48 hours of treatment. Control blood cultures were negative after day 1, 3 83 and 5 of treatment. Cerebral ultrasound examination controls were normal for 84 both infants. At day 41 of life Twin 1 developed septic syndrome with parotitis 85 and was transferred to the NICU. Blood culture was positive for GBS. Cardiac 86 ultrasound examination was normal. Antibiotic therapy with cefotaxime 87 (200mg/kg/day) and tobramycin $(5 \mathrm{mg} / \mathrm{kg} /$ day) was initiated. At day 7 of 88 infection tomodensitometry examination identified cerebral microabcess and 89 modification of the antibiotherapy ensued, with the administration of 90 ciprofloxacin ( $30 \mathrm{mg} / \mathrm{kg} /$ day) associated with cefotaxime ( $250 \mathrm{mg} / \mathrm{kg} / \mathrm{day})$ for 3

91 weeks. Then oral amoxicillin was initiated for 3 additional weeks. Mastitis was

92 diagnosed in the infants' mother 24 hours following discovery of GBS infection

93 in Twin 1 (day 42). Milk culture tested positive for GBS and the maternal 94 infection was treated with amoxicillin for 10 days. Breastfeeding was 
95 suspended and a 10- day preventive oral amoxicillin treatment given to the

96 non- infected twin (confirmed via negative blood and CSF cultures as well as

97 negative CRP controls). Following this infection, the infants remained on

98 pasteurized breast milk. Follow- up at one year showed no cerebral anomalies

99 upon ultrasound examination in association with normal neurological

100 examinations at 1 year of life.

101

102 Analysis revealed all strains as belonging to serotype III. Epidemiological 103 relationships between maternal and neonatal GBS isolates were investigated

104 by pulsed-field gel electrophoresis (PFGE) of DNA restricted with Smal [11].

105 Analysis was conducted on maternal vaginal and raw breast milk isolates (2

106 isolates), a single Twin 2 blood culture isolate (1 isolate), and on Twin 1 CSF

107 and first- and -second blood culture isolates (3 isolates). All six isolates

108 displayed identical PFGE patterns, revealing their genetic relationship (figure $1091 \mathrm{~A})$.

110 Characterization of isolate virulence was conducted by multiplex PCR

111 according to primers and method previously described [11, 12]. First,

112 amplification of the tRNA gene clusters at the 3 ' end of rRNA operons

113 produced a unique fragment of $1.2 \mathrm{~Kb}$ (figure 1B); second, hy/B amplification

114 produced a $0.3 \mathrm{~Kb}$ fragment, showing no IS1548 insertion within the gene

115 (figure 1B). This pattern was correlated to the invasive phylogenetic division I

116 defined by Musser et al. in multilocus enzyme electrophoresis (MLEE)

117 analysis $[8,10]$.

118

\section{Discussion}

121 Cases reporting neonatal late and recurrent group B streptococcal disease 122 associated with raw maternal milk are rare, and few are the studies in which 
123 genetic evidence is proposed for this scenario $[2,7,13]$. In our case, not only

124 was total DNA macrorestriction analysis conducted, showing indistinguishable

125 patterns for the six isolates, but additional genetic analysis also revealed that

126 the GBS isolates belonged to a particularly virulent clone shown to produce

127 more extracellular neuraminidase [8]. These isolates, as $90 \%$ of the strains

128 responsible for late onset disease [3], belonged to serotype III.

130 If the physiopathology of early onset GBS disease is well-documented, little is

131 known about late or recurrent GBS infections. This case offers a novel

132 hypothesis explaining how GBS can cause neonatal infection from 7 days to 3

133 months following delivery.

134 In most of the rare cases described [7,9], there were no signs of maternal 135 mastitis, indicating a silent maternal duct colonization. Moreover, National 136 Committee of Hygiene guidelines do not systematically screen for GBS in the 137 raw maternal milk supply [1]. These may be two reasons for the 138 underestimation of maternal milk as a source of GBS infection. In the present 139 case, genetic analysis affords evidence for maternal milk as the source of 140 neonatal GBS infection. A circular process was hypothesized by Kotiw et al

141 [7]. GBS initially colonizes the neonate's oropharynx mucosa from perinatal or 142 other sources, infecting maternal ducts during breastfeeding. The organism 143 multiplies in the milk ducts. As the microbial concentration increases in the 144 milk, the infant is re-infected during breastfeeding. Mastitis may or may not be 145 present [7]. However Olver et al described cases of GBS infection in preterm 146 infants fed with maternal milk via nasogastric tube alone [9]. Prematurity is a 147 recognized predisposing factor to GBS infection although breast milk 148 transmission was also described in term infants [4].

149 In our unit, expressed mother's milk is systematically pasteurized and frozen

150 for conservation in our lactarium, and each specimen of milk is screened for 
151 bacteria before administration to preterm infants. However, preterm infants

152 might also receive raw, freshly-expressed breast milk from their mothers

153 present in the unit. When a preterm infant falls clinically ill while the mother is

154 breastfeeding, the mother's milk should be cultured to rule out or to document

155 possible breast milk transmission. Mother's milk feedings should be

156 suspended while providing banked milk pending culture result. If breast milk is

157 positive for GBS, adequate antibiotherapy should also be prescribed for the

158 mother. Byrne et al reported that it is possible to give the mother the

159 opportunity to continue breastfeeding as desired ; she can be encouraged to

160 maintain her milk supply by pumping and discarding milk until appropriate

161 treatment is completed and negative breast milk cultures are obtained [4].

163 Asymptomatic excretion of GBS in breast milk may be an under-recognised 164 cause of neonatal and recurrent infection. Recommendations should be 165 established to prevent these infections, notably in the case of multiple births: $1661 /$ treatment of both twins; 2 / recognition of the possibility of GBS breast milk 167 infection in late onset or recurrent infection; 3/ suspension of breastfeeding 168 upon suspicion of GBS breast milk infection in both of the children; 4/ search 169 for GBS colonization in both mother and children.

170 However, it should also be noted that use of human milk in the intensive care

171 nursery decreases the incidence of nosocomial sepsis [5] and breastfeeding 172 should still be considered as the most appropriate nutrition for babies and 173 preterm infants [1].

175 Conflict of interest statement

176 All authors, no conflict of interest. 


\section{References}

180 1. Anonymous (1997) Breastfeeding and the use of human milk. American 181 Academy of Pediatrics. Work Group on Breastfeeding. Pediatrics 100: 10351829

183 2. Atkins JT, Heresi GP, Coque TM et al (1998) Recurrent group B streptococcal 184 disease in infants: Who should receive rifampin? J Pediatr 132: 537-9

185 3. Baker CJ (1997) Group B streptococcal infections. Clin Perinatol 24: 59-70

186 4. Byrne PA, Miller C, Justus K (2006) Neonatal group B streptococcal infection 187 related to breast milk. Breastfeed Med 1: 263-70

188 5. el-Mohandes AE, Picard MB, Simmens SJ et al (1997) Use of human milk in 189 the intensive care nursery decreases the incidence of nosocomial sepsis. $\mathrm{J}$ 190 Perinatol 17: 130-4

191 6. Klein JO (2001) Bacterial sepsis and meningitis. Remington JS, Klein JO, 192 eds. Infectious Disease of the fetus and newborn infant: 943-948

193 7. Kotiw M, Zhang GW, Daggard G et al (2003) Late-onset and recurrent 194 neonatal Group B streptococcal disease associated with breast-milk 195 transmission. Pediatr Dev Pathol 6: 251-6

196 8. Musser JM, Mattingly SJ, Quentin R et al (1989) Identification of a high197 virulence clone of type III Streptococcus agalactiae (group B Streptococcus) 198 causing invasive neonatal disease. Proc Natl Acad Sci U S A 86: 4731-5

199 9. Olver WJ, Bond DW, Boswell TC et al (2000) Neonatal group B streptococcal 200 disease associated with infected breast milk. Arch Dis Child Fetal Neonatal 201 Ed 83: F48-9

202 10. Quentin R, Huet H, Wang FS et al (1995) Characterization of Streptococcus 203 agalactiae strains by multilocus enzyme genotype and serotype: 204 identification of multiple virulent clone families that cause invasive neonatal 205 disease. J Clin Microbiol 33: 2576-81 
206 11. Rolland K, Marois C, Siquier V et al (1999) Genetic features of 207 Streptococcus agalactiae strains causing severe neonatal infections, as 208 revealed by pulsed-field gel electrophoresis and hylB gene analysis. J Clin 209 Microbiol 37: 1892-8

210 12. Rolland $K$, Mereghetti $L$, Watt $S$ et al (2002) tRNA gene clusters at the $3^{\prime}$ 211 end of rRNA operons are specific to virulent subgroups of Streptococcus 212 agalactiae strains, as demonstrated by molecular differential analysis at the 213 population level. Microbiology 148: 1493-9

214 13. Wang LY, Chen CT, Liu WH et al (2007) Recurrent neonatal group B 215 streptococcal disease associated with infected breast milk. Clin Pediatr 216 (Phila) 46: 547-9 
221 Figure 1

222 A. Pulsed-field gel electrophoresis (PFGE) of DNA restricted with Smal of 223 maternal and neonatal GBS isolates. All six isolates displayed identical PFGE 224 patterns, showing their genetic relationship. Molecular weight (MW) ; maternal 225 vaginal isolate (lane 1) ; Twin 1 CSF (lane 2) ; maternal raw breast milk isolate 226 (lane 3) ; first (lane 4) and second (lane 5) Twin 1 blood culture isolates, and 227 Twin 2 blood culture isolate (lane 6).

228 B. Ethidium bromide stain of $2 \%$ agarose gel showing multiplex PCR products 229 for the GBS clinical isolates. Amplification of the tRNA gene clusters at the 3' 230 end of rRNA operons produced a unique fragment of $1.2 \mathrm{~Kb}$; amplification 231 hylB gene produced a $0.3 \mathrm{~Kb}$ fragment, showing no IS1548 insertion within the 232 gene. This pattern was correlated to the invasive phylogenetic division I 233 defined by Musser et al. in multilocus enzyme electrophoresis (MLEE) 234 analysis $[8,12] . \mathrm{MW}$, molecular weight ; lane 1, maternal vaginal isolate ; lane 235 2, twin 1 CSF isolate ; lane 3, maternal raw breast milk isolate ; lanes 4 and 5 , 236 first and second twin 1 blood culture isolates. 

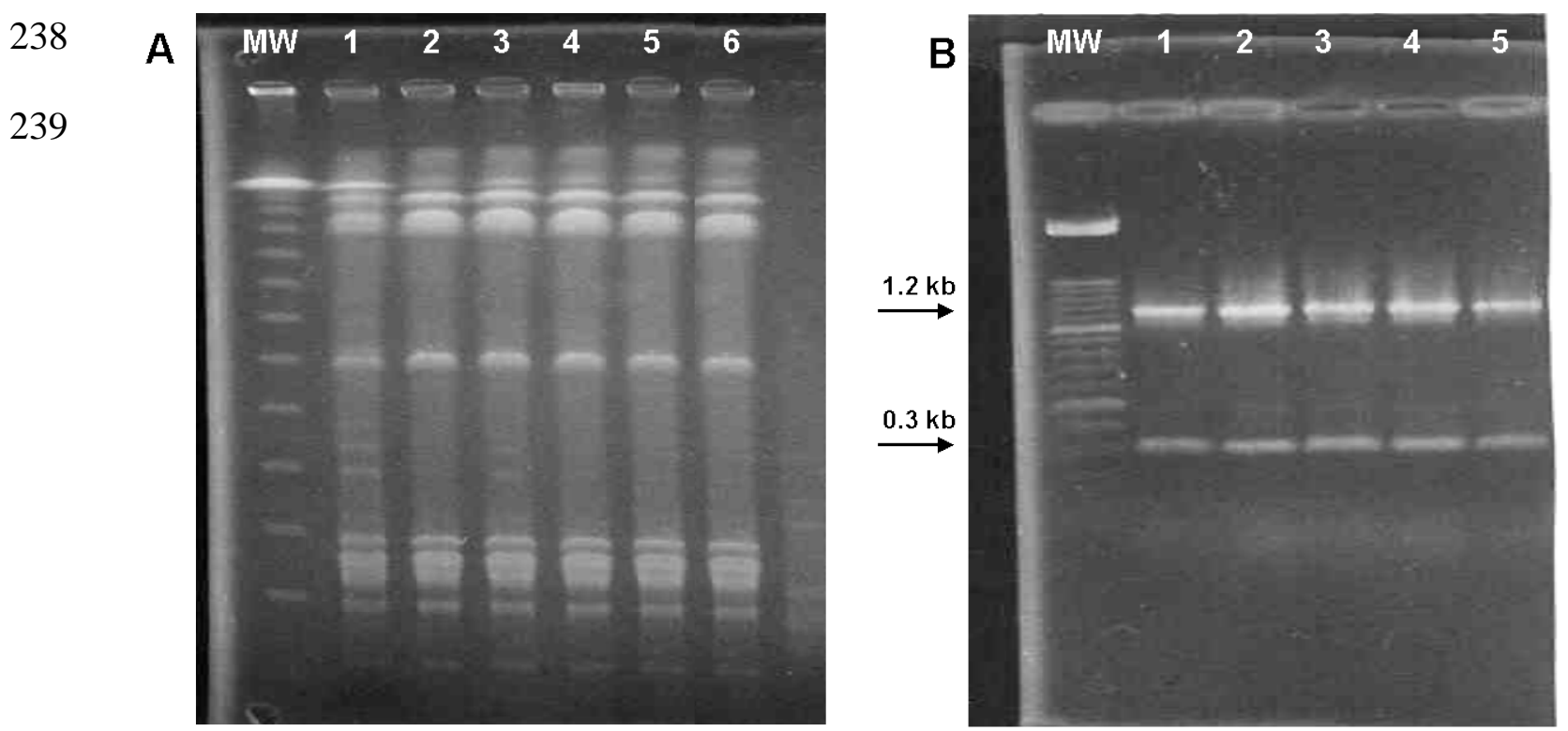